\title{
Visual-Motor Maturity and Executive Functions in Schoolchildren ${ }^{1}$
}

\author{
Ana Luisa Silva de Oliveira² \\ Universidade Federal de Ciências \\ da Saúde de Porto Alegre, \\ Porto Alegre-RS, Brazil \\ Laura Uberti Mallmann \\ Universidade Federal de Ciências \\ da Saúde de Porto Alegre, \\ Porto Alegre-RS, Brazil
}

\author{
Vanessa Kaiser \\ Universidade Federal de Ciências \\ da Saúde de Porto Alegre, \\ Porto Alegre-RS, Brazil \\ Janice Luisa Lukrafka \\ Universidade Federal de Ciências \\ da Saúde de Porto Alegre, \\ Porto Alegre-RS, Brazil
}

\author{
Thamy de Oliveira Azambuja \\ Universidade Federal de Ciências \\ da Saúde de Porto Alegre, \\ Porto Alegre-RS, Brazil \\ Caroline Tozzi Reppold \\ Universidade Federal de Ciências \\ da Saúde de Porto Alegre, \\ Porto Alegre-RS, Brazil
}

\begin{abstract}
Visual-motor maturity and executive functions are closely related in the child development process. This study aimed to investigate the relation between visual-motor abilities and executive functions in 83 healthy children between 7 and 10 years old. The tools used were the Bender Gestalt Visual-Motor Test - Gradual Scoring System (B-GSS), Wisconsin Card Sorting Test (WCST), Raven's Progressive Matrices (RPM), and Rey-Osterrieth Complex Figure (ROCF). The correlation between the B-GSS and WCST scores was significantly negative $(r=-.23, p<.033)$, while ROCF variables, such as Total Memory and Total Copy, had a moderate, significant correlation with total B-GSS score $(r=-.55, p<.001 ; r=-.44, p<.001$, respectively). The results empirically show the relation between executive functions and visual-motor maturity and are discussed in face of developmental neuropsychology.
\end{abstract}

Keywords: perceptual motor development, cognitive neuropsychology, Bender-Gestalt Test, Wisconsin card sorting test

\section{Maturidade Visomotora e Funções Executivas em Escolares}

\begin{abstract}
Resumo: A maturidade visomotora e as funções executivas estão intimamente relacionadas no processo de desenvolvimento infantil. O objetivo deste estudo foi investigar a relação entre habilidades visomotoras e funções executivas em 83 crianças hígidas, de 7 a 10 anos. Os instrumentos utilizados foram Teste Gestáltico Visomotor de Bender - Sistema de Pontuação Gradual (B-GSS), Teste Wisconsin de Classificação de Cartas (WCST), Matrizes Progressivas de Raven (RPM) e Rey- Osterrieth Figura Complexa Test (ROCF). A correlação entre os escores de B-GSS e WCST foi negativa e significativa $(r=0,23, p<0,033)$ e variáveis do ROCF, como Cópia Total e Memória Total apresentaram correlação moderada e significativa com o escore total do B-GSS $(r=-0,55, p<0,001 ; r=-0,44, p<$ 0,001 , respectivamente). Os resultados evidenciam empiricamente a relação entre funções executivas e maturidade visomotora e são discutidos à luz da neuropsicologia do desenvolvimento.
\end{abstract}

Palavras-chave: desenvolvimento percetomotor, neuropsicologia cognitiva, Teste Gestáltico de Bender, teste Wisconsin de classificação de cartas

\section{Madurez Visomotora y Funciones Ejecutivas en Escolares}

Resumen: La madurez visual-motora y las funciones ejecutivas están estrechamente relacionados en el proceso de desarrollo del niño. El objetivo de este estudio fue investigar la relación entre habilidades visomotoras y funciones ejecutivas en 83 niños sanos, de 7-10 años. Los instrumentos utilizados fueron Prueba Gestáltica Visomotora de Bender - Sistema de Puntuación Gradual (B-GSS), Prueba Wisconsin de Clasificación de Cartas (WCST), Matrices Progresivas de Raven (RPM) y Prueba Rey- Osterrieth Figura Compleja (ROCF). La correlación entre las puntuaciones B-GSS y WCST fue negativa y significativa $(r=0,23, p<0,033)$ y ROCF variables, como Copiar y Memoria Total mostraron correlación moderada y significativa con la puntuación total de la B-GSS ( $r=$ $-0,55, p<0,001 ; r=-0,44, p<0,001$, respectivamente). Los resultados demuestran empíricamente la relación entre las funciones ejecutivas y la madurez visomotora y se discuten a la luz de la neuropsicología del desarrollo.

Palabras clave: desarrollo perceptomotor, neuropsicología cognitiva , test de Bender-Gestalt, Wisconsin

\footnotetext{
${ }^{1}$ Paper derived from the first author's master's thesis under supervision of the sixth author, defended in 2013, at the Graduate Program in Rehabilitation Sciences of the Universidade Federal de Ciências da Saúde de Porto Alegre. Support: Productivity scholarship by the National Council for Scientific and Technological Development (CNPq) made available to the sixth author (Grant \# 304204/2013-7).

${ }^{2}$ Correspondence address:

Ana Luisa Silva de Oliveira. Rua Sarmento Leite, 245, Centro Histórico. CEP 9005-170. Porto Alegre-RS, Brazil. E-mail: analuisa_fisio@yahoo.com.br
}

Throughout life, human beings gradually acquire the necessary visual-motor skills for recognizing objects, including their own bodies, and how to position themselves according to the objects. This action implies not only being able to recognize spatial parameters of the objects (volume, direction, movement) and their affinities with the surrounding world, but also knowing how to move around a previously explored space (Chiappedi et al., 2013; Gil, 2002). Visuoconstructive abilities are related to the capacity to perform formative and constructive activities that allow 
carrying out actions with motor purposes (Malloy-Diniz, Fuentes, Mattos, \& Abreu, 2010). For an individual to perform such functions, the following processes must be consolidated: visual perception, spatial reasoning, establishing plans or goals, adequate motor behavior, and ability to monitor selfperformance (Malloy-Diniz et al., 2010).

The progressive maturation of the cerebral cortex, especially in the first 24-36 months of life, gradually improves the organization of psychomotor functions. This evolution of the central nervous system (CNS), associated with motor skills acquired by environmental stimuli which develop sensorimotor experiences, visualmotor coordination, visuospatial perception, balance, and consciousness for the constitution of the body schema, along with social interactions that are indispensable for the processes of learning and literacy (Bonifacci, 2004; Passos, Caramelli, Benseñor, Giatti, \& Barreto, 2014; Van Waelvelde, De Weerdt, De Cock, \& Smits-Engels, 2004).

Souza and Capellini (2011) pointed out that the visual-motor perception process results from the combination of multiple neurocognitive skills, namely: visual-motor maturity, visual perception capacity (such as eye-hand coordination), visuospatial relations, figureground perception, and shape constancy. A relation can be traced between perceptual and motor aspects (especially visual-motor coordination) and learning difficulties. This association has been widely discussed in the literature (Bartholomeu \& Sisto, 2008; Böhm, Lundequist, \& Smedler, 2010; Martin, Tigera, Denckla, \& Mahone, 2010; Schreiber, Possin, Girard, \& Rey-Casserly, 2014; Silva, Beltrame, A. V. P. Oliveira, \& Sperandio, 2012) in order to detect deficits in school performance early on, since children face new challenges as they grow.

The interplay between perceptual and motor aspects, especially visual-motor coordination and learning disabilities, is well discussed in the literature (Carvalho \& Magalhães, 2004; Souza \& Capellini, 2011; Silva et al., 2012). Such data indicate the importance of assessing the perceptuomotor performance not only in populations of individuals exposed to risks but also in children whose development is considered typical (Carvalho \& Magalhães, 2004). There are several specific tools to evaluate visual-motor skills. One system proposed for assessing the perceptuomotor skills of schoolchildren is the Bender Visual-Motor Gestalt Test (BVMGT) (Noronha \& Mattos, 2006). Since Bender figures were created, several interpretation systems have been developed, including the Koppitz version, which is one of the main and most widely used correction methods in clinical psychology. Some studies correlate the neuropsychology data and Bender's test, e.g., Bartholomeu and Sisto (2008), in which the authors sought evidence of convergent validity between BVMGT, assessed by the B-GSS, and the Human Figure Drawing (HFD), an intelligence test.

On the other hand, executive functions (EFs) consist of a set of cognitive skills that, when associated, are designed to execute an oriented behavior towards previously established purposes, thus allowing the individuals to directly interact with the world and to organize tasks, such as setting goals, evaluating the efficiency and adequacy of the behavior according to situations, and abandoning improper strategies for the sake of more appropriate or convenient ones to solve problems (Cruz, Camargos-Junior, \& Rocha, 2013; MalloyDiniz et al., 2010; Sesma, Mahone, Levine, Eason, \& Cutting, 2009; Tonietto, Wagner, Trentini, Sperb, \& Parente, 2011; Yasumura, Inagaki, \& Hiraki, 2014). EFs are responsible for articulating subordinated functions such as thinking, working memory, planning, attention and inhibitory control, and cognitive flexibility, among others, which guide the execution of a behavior with specific aims (Ferrier, Bassett, \& Denham, 2014; Miyake \& Friedman, 2012; Olaithe \& Bucks, 2013; Skogan et al., 2015).

The psychiatric assessment of EFs involves several procedures, including the use of validated tools - through specific test batteries which comprise all the subdomains of the EFs, or more flexible batteries defined by the examiner - and complementary procedures through interviews, cognitive tasks, observation, and functional assessment of the individual. Given the extent of the skills that depend on EFs, it is not expected that a single type of assessment will be able to evaluate the most complex cognitive aspects of an individual. Therefore, the use of multiple techniques is required for the assessment of the distinct EF subdomains, considering that their deficit may either affect all the executive processes or act in a selective way, affecting only some of the subfunctions (Drake, 2007; Malloy-Diniz et al., 2010).

Among the reasons that have led to the growing interest in studies on child development, the parallels between motor and cognitive development stand out, showing the close relation between what children can learn and what they can accomplish. In face of that, the following are pointed out to justify the present study: (a) the relevance of interdisciplinary action in scientific research; (b) the need for knowing children development stages and the close relations between cognitive and motor functions; (c) the use of validated assessment tools in children interventions so as to investigate and understand the cognitive-motor functioning inherent to the intellectual acquisition process; and (d) the benefits of a detailed assessment of such capacities, which enables the establishment of coherent instructive and interventionist strategies that respect the concepts of continuity (typical maturation process) and individuality of the individuals assessed. Regarding these topics, the main goal of the present study was to look for evidence of an association between aspects of visual-motor perception and executive functions, investigated by specific neurological tests standardized for the Brazilian population, in a sample composed of schoolchildren with typical neurologic development.

\section{Method}

\section{Participants}

This is a cross-sectional study with 83 healthy children, aged between 7 and 10 years, from two public elementary schools in Porto Alegre, Brazil. Schools were chosen by convenience. The exclusion criteria for the sampling were: 
(a) Children diagnosed with cognitive and neurological disorders according to the score obtained in Raven's Progressive Matrices test (those who scored five or less were considered "intellectually disabled"); (b) Children with other biophysical conditions that prevented them from performing psychological tests; (c) Children who did not have the Informed Consent Form signed by their parents or guardians; and (d) Children who did not agree to participate, refusing to sign the Informed Assent Form. The data were collected from 94 participants, but only 83 met the inclusion criteria.

\section{Instruments}

The Neuropsychological Assessment Battery was composed of the following tests adapted and standardized to Brazilian samples:

Bender Visual-Motor Gestalt Test - Gradual Scoring System (B-GSS). Developed by Sisto, Noronha, and Santos (2006), the B-GSS is used to evaluate the maturational aspects of visual-motor skills of children aged six to ten years. In this system, the functions are measured only by analyzing the shape distortion of the images proposed by Bender. Application time usually does not exceed 15 minutes, although there is no predetermined time limit. Validity studies have been performed with respect to the internal structure and dimensionality of the items. The instrument has good internal consistency with Cronbach's alpha for "all ages" estimated at .80 .

Rey-Osterrieth Complex Figure Test (ROCF). Standardized by M. S. Oliveira and Rigoni (2010), ROCF allows assessing the visual-spatial organization skills, planning and development of execution strategies, as well as non-verbal memory. It consists of a complex geometric figure - a large rectangle, horizontal and vertical bisectors, two diagonals, and additional geometric details in and outside the large rectangle. The instrument has good internal consistency with Cronbach's alpha estimated at .897 in "copy" and .831 in "reproduction of memory".

Wisconsin Card Sorting Test (WCST). With norms proposed by Trentini, Argimon, M. S. Oliveira and Werlang (2006), WCST is considered the gold standard for exams intended to assess executive functions. In this test, 128 cards are presented to the subjects (one at a time) and should be grouped with one of four target cards - the subject assigns cards with simple geometric shapes to three distinct categories: shape, color, and number. However, the classification principle is not revealed beforehand and the subject must establish it by trial and error. Each time the subject chooses a card, the examiner will inform him/her if the choice is "right" or "wrong." Once the individual has learned how to choose a dimension and gets it right for 10 consecutive times within these same criteria, the examiner changes the rules without warning. In addition, the WCST also provides information about the cognitive inflexibility, categorization processes, impulsivity, and attention. The instrument's manual presents the validity and reliability studies for the Brazilian population. The generalizability coefficients of WCST scores range from
.66 to .75 , with a mean and median of .70 demonstrating satisfactory reliability in all scores.

Raven's Progressive Matrices Test (RPM). Standardized for the population of Rio Grande do Sul by Bandeira, Alves, Giacomel, and Lorenzato (2004), RPM is composed of three sets of 12 items: $\mathrm{A}, \mathrm{AB}$, and $\mathrm{B}$, which are designed to measure only one component of the " $g$ " factor, the educative ability. According to Angelini, Alves, Custódio, J. L. M. Duarte, and W. F. Duarte (1999) and Bandeira et al. (2004), educative ability refers to the ability to extract insights from previously known and perceived situations and to develop new understandings for what is not immediately obvious through non-verbal constructs. The instrument's manual presents accuracy and validation studies, moreover, regarding internal consistency, all item-total correlations of the instrument are significant, with the largest share of item correlations between .30 and .80 .

\section{Procedure}

Data collection. Data collection was directly performed in the schools included in this study. The tests were administered in classrooms made available by the principal of each institution, with the condition that the place had a tranquil and well-ventilated environment, with appropriate lighting and free of external interferences. Upon authorization, tests began being administered, in two meetings, individually (RPM, ROCF, and WCST), i.e., one examiner per examinee, and collectively (B-GSS).

Data analysis. The results were initially included in a database in the software Excel (version 2010). Afterwards, they were analyzed using the software Statistical Package for Social Sciences (SPSS) version 20. To test for normality of the data distribution, the KolmogorovSmirnov test was applied. For the analyses of correlation between the scores, Pearson Correlation was employed in case of normal distribution and/or Spearman Correlation was employed in case of non-normal data distribution.

\section{Ethical Considerations}

This study was approved by the Research Ethics Committee of the Universidade Federal de Ciências da Saúde de Porto Alegre (UFCSPA) under protocol 1437/11 on September 15th, 2011. In the first contact with the classes, the Informed Consent Form and the Informed Assent Form were distributed. The neuropsychological evaluation was done by researchers trained by a psychologist regarding the administration and interpretation of tools, with the objective of attaining satisfactory interobserver reliability.

\section{Results}

Results were analyzed according to the intended objectives, employing descriptive and inferential statistical methods. Table 1 shows the sample characterization regarding 
Table 1

Sample Characterization for Age, Gender, Laterality, and Schooling

\begin{tabular}{ccc}
\hline Variables & Absolute & Relative Frequency (\%) \\
& Frequency & \\
\hline
\end{tabular}

Age (years)

$\begin{array}{lll}7 & 24 & 28.92 \\ 8 & 22 & 26.51 \\ 9 & 26 & 31.33 \\ 10 & 11 & 13.25\end{array}$

Gender

Female

50

60.2

Male

33

39.8

Schooling

2nd Grade

33

3rd Grade

23

39.8

4th Grade

27

Laterality

Right

Left

78

94

5

age, gender, laterality, and schooling, demonstrating that the sample had non-normal data distribution.

The children had an average total score $(\mathrm{A}+\mathrm{AB}+\mathrm{B})$ of $M=24.83(S D=5.33)$ in RPM, with the task execution time estimated at $6.16(3.56-15.32)$. Twenty-eight $(33.7 \%)$ children were classified as level II, indicating aboveaverage intellectual capacity. None of the children was classified as level V (score equal to or less than 5), which indicates an intellectually deficient pattern and would have excluded the child from this study. The ROCF scores had a parametric distribution, represented by mean (SD): Total Copy $M=17.80(S D=6.082)$; Copy Time $M=6.30(S D=$ 2.623); Total Memory $M=8.20(S D=5.158)$; and Memory Time $M=3.69(S D=2.366)$. Table 2 shows the scores obtained in assessments of visual-motor maturity and EFs, respectively. The mean score in the B-GSS was 11.19 with $S D=3.93$. The median value was 11 , indicating that $50 \%$ of the sample scored up to 11 points and the minimum and maximum scores were 1 and 21. In the sorting of the quartiles, the least representative score was $4(4.8 \%)$, indicating a quartile below 25 , and the most representative was 19 (22.9\%), indicating a quartile above 90. Most of the answers were classified as above quartile 75 . Considering the performance in the WCST, not all the aspects showed normality of data; therefore, data were expressed as median (min-max). Those which had parametric distribution were expressed as mean $(S D)$, and the total correct number was $M=53.98(S D=23.189)$.

In order to verify a possible relation between the B-GSS and RPM, a proof of correlation was proposed, considering the scores obtained in these two tests, taking into account

the age variable for possible differences in the test results. There was a significant positive correlation between RPM and B-GSS total scores only in the 7-year-old group ( $r$ $=-.59, p<.002)$. No significant correlation between the scores was found in other age groups.

To investigate the relation between the constructs visuomotor maturity and EFs, associations between the B-GSS and WCST scores were sought by correlating the total score of the former with the total values of the latter. The result of the correlation between the B-GSS and WCST (total number of correct answers) was weak, negative, and significant ( $r=$ $-.23, p<.033$ ), suggesting that the higher the maturation state of EFs, the lower the number of errors or distortions in the Bender-Gestalt test, as shown in Table 3. The results regarding conceptual level $(r=-.27, p<.01)$ and number of completed categories $\left(r^{\prime}=.30, p<.006\right)$ in the WCST are also significantly correlated with the total B-GSS scores.

Table 2

Description of Variables in the B-GSS and WCST

\begin{tabular}{|c|c|c|}
\hline Test & Variable & Results \\
\hline \multicolumn{3}{|c|}{ B-GSS } \\
\hline & Total & $M=11.19, S D=3.93$ \\
\hline & \multicolumn{2}{|c|}{ Quartile } \\
\hline & Less than 25 & $4(4.8 \%)$ \\
\hline & Equal to 25 & $5(6 \%)$ \\
\hline & Between 25 and 50 & $6(7.2 \%)$ \\
\hline & Equal to 50 & $7(8.4 \%)$ \\
\hline & Between 50 and 75 & $11(13.2 \%)$ \\
\hline & Equal to 75 & $8(9.6 \%)$ \\
\hline & Between 75 and 90 & $16(19.3 \%)$ \\
\hline & Equal to 90 & $7(8.4 \%)$ \\
\hline & Above 90 & $19(22.9 \%)$ \\
\hline \multicolumn{3}{|c|}{ WCST } \\
\hline & $\begin{array}{l}\text { Number of assays } \\
\text { administered }\end{array}$ & $128(0-128)$ \\
\hline & Total correct number & $M=53.98, S D=23.189$ \\
\hline & Total number of errors & $M=59.34, S D=27.845$ \\
\hline & Perseverative answers & $39(0-127)$ \\
\hline & Perseverative errors & $29(0-115)$ \\
\hline & $\begin{array}{c}\text { Non-perseverative } \\
\text { errors }\end{array}$ & $M=24.1, S D=18.841$ \\
\hline & Conceptual level & $M=36.93, S D=24.241$ \\
\hline & $\begin{array}{c}\text { Number of completed } \\
\text { categories }\end{array}$ & $M=2.53, S D=2.068$ \\
\hline & $\begin{array}{l}\text { Assays to complete the } \\
1 \text { st category }\end{array}$ & $2(0-6)$ \\
\hline & $\begin{array}{l}\text { Failure to maintain } \\
\text { context }\end{array}$ & $1(0-5)$ \\
\hline & Learning to learn & $1(-17-21)$ \\
\hline
\end{tabular}

Note. Data with parametric distribution are expressed as mean $(S D)$. Values with nonparametric distribution are presented as median (minimum-maximum). In quartile categorization, the results are presented as absolute and relative frequencies $(\mathrm{n} / \%)$. 
Table 3

Correlation Between the B-GSS and WCST

\begin{tabular}{|c|c|c|}
\hline WCST & & -GSS Total \\
\hline \multirow[t]{2}{*}{ Total correct number } & $r$ & -.234 \\
\hline & $p$ & $.033^{*}$ \\
\hline \multirow[t]{2}{*}{ Non-perseverative errors } & $r$ & -.025 \\
\hline & $p$ & .826 \\
\hline \multirow[t]{2}{*}{ Total number of errors } & $r$ & .118 \\
\hline & $p$ & .289 \\
\hline \multirow[t]{2}{*}{ Conceptual level } & $r$ & -.279 \\
\hline & $p$ & $.011^{*}$ \\
\hline \multirow[t]{2}{*}{ Number of completed categories } & r' & .301 \\
\hline & $p$ & $.006 * *$ \\
\hline \multirow[t]{2}{*}{ Number of assays administered } & $\mathrm{r}^{\prime}$ & .049 \\
\hline & $p$ & .659 \\
\hline \multirow[t]{2}{*}{ Perseverative answers } & r' & .144 \\
\hline & $p$ & .193 \\
\hline \multirow[t]{2}{*}{ Perseverative errors } & $\mathrm{r}^{\prime}$ & .158 \\
\hline & $p$ & .154 \\
\hline \multirow[t]{2}{*}{ Assays to complete the 1 st category } & $\mathrm{r}^{\prime}$ & .017 \\
\hline & $p$ & .881 \\
\hline \multirow[t]{2}{*}{ Failure to mantain context } & $\mathrm{r}^{\prime}$ & -.028 \\
\hline & $p$ & .8 \\
\hline \multirow[t]{2}{*}{ Learning to learn } & r' & -.144 \\
\hline & $p$ & .194 \\
\hline
\end{tabular}

Note. $r=$ Pearson correlation; $p=$ significance level; $r$ ' = Spearman correlation.

*Significant correlation at .05 level. **Significant correlation at .01 level.

Regarding the values obtained by correlation between the B-GSS and ROCF (memory), the scores for Total Copy $(r=-.55$, $p<.001)$ and Total Memory $(r=-.44, p<.001)$ had a moderate, significant correlation with the total B-GSS score, indicating that working memory is related with the maturation of visual-motor skills. That is, the better the performance in the ROCF, both in copy execution and in memory reproduction, the fewer the errors in the B-GSS.

Table 4 describes the comparisons among the total scores of all the tools composing the neuropsychologic battery of this study regarding the children's age. Results were analyzed by one-way ANOVA, which indicated statistic significance, with $p$ $<.001$ for all the tests (B-GSS, ROCF, and RPM) except for the 11 components of the WCST. To verify the statistically significant differences among age groups, Tukey's post-hoc test was applied. For the Bender-Gestalt test, there was no difference only between the groups aged 7 and 8 . Yet, for RPM, the 7-year-old group differs from all the others, but the other three groups do not differ among themselves. For Rey-Osterrieth Complex Figures, differences were found in the measurement of copy accuracy comparing the means of the 7-year-old group with the 8-, 9-, and 10-yearold groups. For memory measurement, differences were found comparing the means of the 7-year-old group with the 9- and 10-year-old groups, while the 8-year-old group differed from the 9 - and 10-year-old groups. The performance did not differ when comparing the groups aged 7 and 8 or when comparing the groups aged 9 and 10 .

Table 4

Comparison Among Tests According to Children Age

\begin{tabular}{lccccccccc}
\hline & \multicolumn{4}{c}{ B-GSS Total } & \multicolumn{2}{c}{ RPM Total } & \multicolumn{2}{c}{ ROCF Total Copy } & \multicolumn{2}{c}{ ROCF Total Memory } \\
\hline Age & $N$ & $M$ & $S D$ & $M$ & $S D$ & $M$ & $S D$ & $M$ & $S D$ \\
\hline 7 & 24 & $13.67^{\text {cd }}$ & 3.73 & $20.5^{\text {bd }}$ & 4.98 & $14.83^{\text {cd }}$ & 4.95 & $6^{\text {cd }}$ & 3.77 \\
8 & 22 & $12.36^{\text {cd }}$ & 3.20 & $26.55^{\text {a }}$ & 5.61 & $16.02^{\text {c }}$ & 5.57 & $6.43^{\text {cd }}$ & 4.09 \\
9 & 26 & $9.88^{\text {abd }}$ & 2.64 & $26.42^{\mathrm{a}}$ & 3.57 & $20.52^{\text {ab }}$ & 5.58 & $10.23^{\text {ac }}$ & 5.43 \\
10 & 11 & $6.54^{\text {abc }}$ & 3.14 & $27.09^{\mathrm{a}}$ & 3.67 & $21.36^{\mathrm{a}}$ & 6.52 & $11.73^{\mathrm{ab}}$ & 5.78 \\
\hline
\end{tabular}

Note. a, b, c, and d refer, respectively, to the groups of 7, 8, 9, and 10 years of age and indicate which groups were statistically different when the means were compared by Tukey's test $(p<.05)$. The results of the WCST are not shown in the table because no significant differences were found among age groups. 


\section{Discussion}

The main goal of the present study was to investigate the relation between visual-motor abilities and executive functions through the Bender Gestalt Visual-Motor Test - Gradual Scoring System (B-GSS) and Wisconsin Card Sorting Test (WCST). Several studies have applied the Bender Visual-Motor Gestalt Test to assess the perceptive and motor aspects both on healthy children and populations with diverse deficits, such as academic (learning, intelligence) and other cognitive/behavioral (Attention Deficit Hyperactivity Disorder) disabilities, using not only the B-GSS system (Bartholomeu \& Sisto, 2008; Sisto et al., 2006) but also the Koppitz version (Noronha \& Mattos, 2006). However, it is important to point out that no studies were found relating the B-GSS with WCST. In order to study the development of visual-motor skills and executive functions in schoolchildren, searching for evidence of relations between these tools, the results of the neuropsychological assessments performed in this study will be discussed hereafter.

The B-GSS is related with intelligence measures, such as the $\mathrm{g}$ factor, through Raven's Progressive Matrices Test (Sisto et al., 2006). Therefore, RPM was used, in this study, to measure the IQ of the individuals and to serve as exclusion criteria for those participants who scored 5 or less in this test, which would indicate an intellectually deficient IQ. The method of RPM score interpretation has the advantage of not assuming that, during childhood, the development of intellectual capacity must necessarily be uniform or symmetrically distributed (Angelini et al., 1999). The research carried out by Bartholomeu and Sisto (2008), in which the authors looked for evidence of validity between the Bender Visual-Motor Gestalt Test, assessed by the B-GSS, and Human Figure Drawing (HFD), according to criteria by Sisto, assumes that the Bender-Gestalt Test could be used to assess intelligence in children. Among the main results of such research is the statistically significant difference $(r=$ $-.56 ; p<.001)$ regarding age in the performance of both tools. Older children made fewer errors than younger ones. In this regard, the age-related results match the data in the present research, in which significant differences were found for mean total B-GSS scores in the 7-year-old group compared to the older groups. This indicates that older children make fewer distortions in B-GSS figures. The authors of that study concluded that the B-GSS estimates children's intellectual capacities and distinguish the ones with above-average intellectual development from those with lower intelligence scores. The results also suggest that intelligence and maturity are interconnected. This is confirmed by the HFD results, which contribute a key amount to Bender variance.

Another skill required for a good cognitive performance is the comprehension of new pieces of information and the ability of remembering the most relevant ones. Regarding this relation, this study sought to assess the working memory, one of the components of executive functioning, through the Rey-Osterrieth Complex Figure Test, as an additional measurement to be related with the B-GSS test. According to M. Oliveira, Rigoni, Andretta, and Moraes, (2004), who validated the ROCF for the Brazilian population, this tool is capable of assessing, besides memory, the visual perception and the development of visual-motor coordination. The results obtained in this study showed that the most common copy type in the ROCF was type IV, indicator of juxtaposition of details. The pattern of juxtaposition of details is characterized by the absence of base tracing, ending in a more or less coherent set (M. S. Oliveira \& Rigoni, 2010, p. 42). According to the manual (p. 42), the pattern of juxtaposition of details is dominant among children from five to ten years of age, with an increasing frequency from four to seven years, reaching its higher frequency at eight and decreasing steadily until it reaches its lower frequency in adulthood.

Since there are several studies carried out with the Bender-Gestalt test, proving that this is a sensitive tool for the assessment of visual-motor maturity. The evolutionary character of the test originally proposed by Bender (1955) has been observed in different correction systems and such character was maintained in the B-GSS. Besides, it is noteworthy that visual perception is intimately connected with the proper development of motor behavior, especially in bimanual tasks or tasks involving the eye-hand system. This important relation may be assessed by the Bender-Gestalt test through the results of task execution.

Regarding executive functioning, the neuropsychological assessment of these functions, per se, is not an easy task, since there is no unique standard tool capable of evaluating them. The WCST is a complex test that demands the regulation and control of several components of EFs for its resolution. Although it was developed and used as a measurement of abstract thinking in normal adult populations, the WCST has been increasingly employed in child neuropsychological assessments, being also one of the gold standards for diagnosing frontal lobe lesions (Cunha et al., 2005).

To measure the EFs of the children in this study's sample, the WCST was administered and its scores identified that the children had a poor performance in task execution. This may be justified by the fact that the subjects of the age group assessed still have immature cortical regions upon which the executive functioning depends. Because various skills involve EFs, a unique tool to assess them is not easily found. According to the literature (Bull, Espy, \& Wiebe, 2008; Drake, 2007; Malloy-Diniz et al., 2010), the tests intended to measure executive functioning should require cognitive effort, use working memory, and be a novel task for the examinee. Thus, the WCST fulfills the requirements for an adequate neuropsychological assessment, allowing the subjects to solve their tasks in a flexible and organized manner. Most of the correlations between the mean total score in the B-GSS and the WCST components were not significant. The significant correlations were weak, indicating that the higher the brain maturational stage of an individual, the fewer the number of distortions in the figures of the B-GSS test.

Among the few studies found that assessed and related the visual-motor maturity and executive function constructs is the one by Böhm et al. (2010), which investigated the relation between these functions in a longitudinal prospective research in a group of 175 preterm infants and a control 
group of 125 infants born at term within the Neonatal Project of hospitals Karolinska and Löwenströnska in Stockholm. The research by Böhm et al., employed a broad battery of neuropsychological tests, among which the Bender-Gestalt Test. The results by Böhm et al. (2010) showed that the scores in the Bender-Gestalt test for preterm infants were below average compared with the control group, indicating that the premature infants had delayed visual-motor competency development and that such delay persists at pre-school age. The data found by Böhm et al. match those in the present study, in which the relation between the visual-motor maturity and executive function constructs, investigated from the association between B-GSS and WCST scores, indicate that the greater the executive function maturity status, the fewer the errors or distortions in B-GSS figures.

As mentioned, EFs articulate subordinated functions such as thinking, attention and inhibitory control, and working memory in order to direct the behavior to task execution (Bull et al., 2008; Tonietto et al., 2011). For a more specific assessment of the working memory of the subjects in this research, the Rey-Osterrieth Complex Figure Test was employed (M. S. Oliveira \& Rigoni, 2010). The precise cognitive operations required for an adequate performance in this tool include visual perception, visuospatial organization, motor functions, and memory reproduction. In this context, the present study proposed to also relate the scores of the B-GSS and ROCF tests. Copy reproduction reflects the percentage of visuospatial organization, whereas memory reproduction reflects the amount of information that is stored and recovered from memory.

The results indicate that there was a statistically significant correlation between the total score in the BenderGestalt test and the richness and accuracy in the ROCF. An inverse correlation was found, indicating that the better the perceptual data grasped by the subject in the copy reproduction in the ROCF test, the lower the total score in the Bender-Gestalt test. These tools had similar features regarding skills assessed by both, such as visuoperceptive functions and visuospatial organization, and they also provided an innovative character through the copying of novel figures.

When comparing the total score of the Bender-Gestalt test, the older children, on average, perform better in test execution. This result indicates that the gradual scoring system is able to differentiate children regarding the severity of the errors committed and their developmental capacity. Analyses showed that there are significant differences between the 7- and 8-year-old age groups when compared to the 9- and 10-year-old groups. These data corroborate the maturational assumption of the tool, which estimate that, as age advances and cognitive functions are typically developed, the performance of visuoperceptive functions and motor coordination are progressively improved. These findings are supported by the current literature (Souza \& Capellini, 2011), as they indicate that the cognitive developmental process is intrinsic to the motor development, and both systems, associated with the environmental stimuli, provide a wide range of experiences not only in the behavioral scope, through social interactions indispensable to the learning and literacy processes, but also in the sensory-motor scope, responsible for decision-making and constitution of the body schema.

The results concerning the comparison of RPM scores among different age groups show that intellectual capacity improves as age advances. Such differences in scoring are more pronounced when comparing the 7-year-old group with the others. Raven's Progressive Matrices measure not only the individual's intelligence, but also the capacity to reduce relations. Such competencies are related with, but not restricted to, the successful academic performance, and also depend on cerebral maturation.

No studies were found correlating the B-GSS and WCST tests for evaluation of, respectively, the visual-motor maturity and executive functioning constructs. Therefore, the present research is innovative and points out the importance of further studies in order to improve the knowledge on this subject.

Besides the relation proposed as the main objective of the study, another relevant piece of data of this research, which was also not found in previous studies, was the relation between the B-GSS and the Rey-Osterrieth Complex Figure test. Results pointed to a moderate correlation between visual-motor maturity and some constructs which the ROCF aims to assess, such as visual apperception, visual-spatial organization, and working memory, the last of which one of the most important subfunctions of EFs. This result justifies the impairment in memory richness and accuracy exhibited by the children evaluated.

Among the study limitations, the fact that the analyses did not consider gender differences and also that there were no private school students in the sample can be mentioned. Another point is the fact that visual-motor maturity was assessed by a recent test, which makes it difficult to find studies with which to compare results. Further research expanding the sample scope and the age of the assessed individuals is suggested.

\section{References}

Angelini, A. L., Alves, I. C. B., Custódio, E. M., Duarte, J. L. M., \& Duarte, W. F. (1999). Matrizes Progressivas Coloridas de Raven: Escala especial [Raven's Progressive Matrices Test: Special scale]. São Paulo, SP: Centro Editor de Testes e Pesquisas em Psicologia.

Bandeira, D. R., Alves, I. C. B., Giacomel, A. E., \& Lorenzatto, L. (2004). Matrizes progressivas coloridas de Raven - escala especial: Normas para Porto Alegre, RS [The Raven's coloured progressive matrices: Norms for Porto Alegre, RS]. Psicologia em Estudo, 9(3), 479-486. doi:10.1590/S1413-73722004000300016

Bartholomeu, D., \& Sisto, F. F. (2008). Maturidade visomotora e inteligência: Um estudo correlacional [Visualmotor maturity and intelligence: A correlational study]. Psicologia: Ciência e Profissão, 28(2), 362-373. doi:10.1590/S1414-98932008000200011

Bender, L. (1955). Test Gestaltico Visomotor (BG): Uso y aplicaciones clínicas [Visual-motor Gestalt Test (BG: 
Use and clinical applications]. Buenos Aires, Argentina: Paidós.

Böhm, B., Lundequist, A., \& Smedler, A.-C. (2010). Visual-motor and executive functions in children born preterm: The Bender Visual Motor Gestalt Test revisited. Scandinavian Journal of Psychology, 51(5), 376-384. doi:10.1111/j.1467-9450.2010.00818.x

Bonifacci, P. (2004). Children with low motor ability have lower visual-motor integration ability but unaffected perceptual skills. Human Movement Science, 23(2), 157168. doi:10.1016/j.humov.2004.08.002

Bull, R., Espy, K. A., \& Wiebe, S. A. (2008). Shortterm memory, working memory, and executive functioning in preschoolers: Longitudinal predictors of mathematical achievement at age 7 years. Developmental Neuropsychology, 33(3), 205-228. doi: $10.1080 / 87565640801982312$

Carvalho, D. J., \& Magalhães, L. C. (2004). A relação entre o desenho da figura humana e a coordenação visomotora em crianças pré-termo aos 6 anos de idade [The relationship between human figure drawing and visualmotor coordination in 6-year-old preterm children]. Revista de Terapia Ocupacional da Universidade de São Paulo, 15(3), 98-105. doi:10.11606/issn.2238-6149. v15i3p98-105

Chiappedi, M., Toraldo, A., Mandrini, S., Scarpina, F., Aquino, M., Magnani, F. G., \& Bejor, M. (2013). Easy quantitative methodology to assess visual-motor skills. Neuropsychiatric Disease and Treatment, 9, 93-100. doi:10.2147/NDT.S37187

Cunha, J. A., Trentini, C. M., Argimon, I., Oliveira, M. S., Werlang, B. G., \& Prieb, R. G. G. (2005). Adaptação e padronização brasileira do Manual do Teste Wisconsin de Classificação de Cartas [Adaptation and standardization of Brazilian Test Manual Wisconsin Card Sorting]. São Paulo, SP: Casa do Psicólogo.

Cruz, L. P., Camargos-Junior, W., \& Rocha, F. L. (2013). The broad autism phenotype in parents of individuals with autism: A systematic review of the literature. Trends in Psychiatry and Psychotherapy, 35(4), 252-263. doi:10.1590/2237-6089-2013-0019

Drake, M. (2007). Introducción a la evaluación neuropsicológica. In D. Burin, M. Drake, \& P. Harris, Evaluación neuropsicológica en adultos [Neuropsychological evaluation in adults] (pp. 27-59). Buenos Aires, Argentina: Paidós.

Ferrier, D. E., Bassett, H. H., \& Denham, S. A. (2014). Relations between executive function and emotionality in preschoolers: Exploring a transitive cognition-emotion linkage. Frontiers in Psychology, 5, 487. doi:10.3389/ fpsyg.2014.00487

Gil, R. (2002). Neuropsicologia [Neuropsychology]. São Paulo, SP: Ed. Santos.

Malloy-Diniz, L. F., Fuentes, D., Mattos, P., \& Abreu, N. (2010). Avaliação neuropsicológica [Neuropsychological assessment]. Porto Alegre, RS: Artmed.

Martin, R., Tigera, C., Denckla, M. B., \& Mahone, E.
M. (2010). Factor structure of paediatric timed motor examination and its relationship with IQ. Developmental Medicine and Child Neurology, 52(8), e188-194. doi:10.1111/j.1469-8749.2010.03670.x

Miyake, A., \& Friedman, N. P. (2012). The nature and organization of individual differences in executive functions: Four general conclusions. Current Directions in Psychological Science, 21(1), 8-14. doi:10.1177/0963721411429458

Noronha, A. P. P., \& Mattos, R. M. C. B. (2006). Koppitz e Bender - sistema de pontuação gradual: Comparação entre sistemas de avaliação [Koppitz and Bender gradual scoring system: Comparison between systems of evaluation]. Psicologia Escolar e Educacional, 10(2), 223-233. doi:10.1590/S1413-85572006000200006

Olaithe, M., \& Bucks, R. S. (2013). Executive dysfunction in OSA before and after treatment: A meta-analysis. Sleep, 36(9), 1297-1305. doi:10.5665/sleep.2950

Oliveira, M., Rigoni, M., Andretta, I., \& Moraes, J. F. (2004). Validação do teste figuras complexas de Rey na população brasileira [Rey Complex Figure validation for the brazilian population]. Avaliação Psicológica, 3(1), 33-38.

Oliveira, M. S., \& Rigoni, M. S. (2010). Figuras Complexas de Rey: Teste de cópia e de reprodução de memória de figuras geométricas complexas [Rey's Complex Figures: Test copy and reproduction memory complex geometries]. São Paulo, SP: Casa do Psicólogo.

Passos, V. M. A., Caramelli, P., Benseñor, I., Giatti, L., \& Barreto, S. M. (2014). Methods of cognitive function investigation in the Longitudinal Study on Adult Health (ELSA-Brasil). São Paulo Medical Journal, 132(3), 170177. doi:10.1590/1516-3180.2014.1323646

Schreiber, J. E., Possin, K. L., Girard, J. M., \& Rey-Casserly, C. (2014). Executive function in children with attention deficit/hyperactivity disorder: The NIH Examiner battery. Journal of the International Neuropsychological Society, 20(1), 41-51. doi:10.1017/S1355617713001100

Sesma, H. W., Mahone, E. M., Levine, T., Eason, S. H., \& Cutting, L. E. (2009). The contribution of executive skills to reading comprehension. Child Neuropsychology, 15(3), 232-246. doi:10.1080/09297040802220029

Silva, J., Beltrame, T. S., Oliveira, A. V. P., \& Sperandio, F. F. (2012). Motor and learning disabilities in school children with low academic performance. Revista Brasileira de Crescimento e Desenvolvimento Humano, 22(1), 41-46. doi:10.1590/S0104-12822012000100006

Sisto, F. F., Noronha, A. P. P., \& Santos, A. A. A. (2006). B-SPG - Teste Gestáltico Viso-Motor de Bender [B-SPGGestalt Visual-Motor Bender Test]. São Paulo, SP: Vetor.

Skogan, A. H., Zeiner, P., Egeland, J., Urnes, A.-G., ReichbornKjennerud, T., \& Aase, H. (2015). Parent ratings of executive function in young preschool children with symptoms of attention-deficit/-hyperactivity disorder. Behavioral and Brain Functions, 11, 16. doi:10.1186/ s12993-015-0060-1

Souza, A. V., \& Capellini, A. S. (2011). Percepção visual 
de escolares com distúrbios de aprendizagem [Visual perception of students with learning disabilities]. Revista de Psicopedagogia, 28(87), 256-261.

Tonietto, L., Wagner, G. P., Trentini, C. M., Sperb, T. M., \& Parente, M. A. M. P. (2011). Interfaces entre funções executivas, linguagem e intencionalidade [Interfaces among executive functions, language and intentionality]. Paidéia (Ribeirão Preto), 21(49), 247-255. doi:10.1590/ S0103-863X2011000200012

Trentini, C. M., Argimon, I. I. L., Oliveira, M. S., \& Werlang, B. G. (2006). O desenvolvimento de normas para o teste Wisconsin de classificação de cartas [Development standards Wisconsin card sorting test]. Avaliação Psicológica, 5(2), 247-250.

Van Waelvelde, H., De Weerdt, W., De Cock, P., \& SmitsEngels, B. C. M. (2004). Association between visual perceptual deficits and motor deficits in children with developmental coordination disorder. Developmental Medicine \& Child Neurology, 46(10), 661-666. doi:10.1111/j.1469-8749.2004.tb00978.x

Yasumura, A., Inagaki, M., \& Hiraki, K. (2014). Relationship between neural activity and executive function: An NIRS Study. ISRN Neuroscience, 2014. doi:10.1155/2014/734952

Ana Luisa Silva de Oliveira holds a Master's degree from the Graduate Program in Rehabilitation Sciences of the Universidade Federal de Ciências da Saúde de Porto Alegre.

Vanessa Kaiser is an undergraduate student in Psychology at the Universidade Federal de Ciências da Saúde de Porto Alegre.

Thamy de Oliveira Azambuja is an undergraduate student in Psychology at the Universidade Federal de Ciências da Saúde de Porto Alegre.

Laura Uberti Mallmann is a Speech-language pathologist graduated from the Universidade Federal de Ciências da Saúde de Porto Alegre.

Janice Luisa Lukrafka is an Associate Professor at the Universidade Federal de Ciências da Saúde de Porto Alegre.

Caroline Tozzi Reppold is an Associate Professor I at the Universidade Federal de Ciências da Saúde de Porto Alegre.

Received: Aug. 4, 2015

1st Revision: Nov. 16, 2015

Approved: Nov. 18, 2015

How to cite this article:

Oliveira, A. L. S., Kaiser, V., Azambuja, T. O., Mallmann, L. U., Lukrafka, J. L., \& Reppold, C. T. (2016). Visual-motor maturity and executive functions in schoolchildren. Paidéia (Ribeirão Preto), 26(64), 215-223. doi:10.1590/198243272664201609 